\title{
SARS-CoV-2 Antibody Binding and Neutralization in Dried Blood Spot Eluates and Paired Plasma
}

\author{
Hannah L. Itell, ${ }^{a, b}$ Haidyn Weight, ${ }^{a}$ Carolyn S. Fish, ${ }^{a}$ Jennifer K. Logue, ${ }^{c}$ Nicholas Franko, ${ }^{c}$ Caitlin R. Wolf, ${ }^{c}$ Denise J. McCulloch, \\ Jared Galloway, ${ }^{d}$ Frederick A. Matsen IV, ${ }^{d}$ Helen Y. Chu, ${ }^{c}$ (D) Julie Overbaugh ${ }^{\mathrm{a}}$ \\ aHuman Biology Division, Fred Hutchinson Cancer Research Center, Seattle, Washington, USA \\ bMolecular and Cellular Biology Graduate Program, University of Washington and Fred Hutchinson Cancer Research Center, Seattle, Washington, USA \\ cDepartment of Medicine, University of Washington, Seattle, Washington, USA \\ apublic Health Sciences Division, Fred Hutchinson Cancer Research Center, Seattle, Washington, USA
}

ABSTRACT Wide-scale assessment of severe acute respiratory syndrome coronavirus 2 (SARS-CoV-2)-specific antibodies is critical to understanding population seroprevalence, correlates of protection, and the longevity of vaccine-elicited responses. Most SARS-CoV-2 studies characterize antibody responses in plasma/sera. While reliable and broadly used, these samples pose several logistical restrictions, such as requiring venipuncture for collection and a cold chain for transportation and storage. Dried blood spots (DBS) overcome these barriers as they can be self-collected by fingerstick and mailed and stored at ambient temperature. Here, we evaluate the suitability of DBS for SARS-CoV-2 antibody assays by comparing several antibody responses between paired plasma and DBS from SARS-CoV-2 convalescent and vaccinated individuals. We found that DBS not only reflected plasma antibody binding by enzyme-linked immunosorbent assay (ELISA) and epitope profiles using phage display, but also yielded SARS-CoV-2 neutralization titers that highly correlated with paired plasma. Neutralization measurement was further streamlined by adapting assays to a high-throughput 384-well format. This study supports the adoption of DBS for numerous SARS-CoV-2 binding and neutralization assays.

IMPORTANCE Plasma and sera isolated from venous blood represent conventional sample types used for the evaluation of SARS-CoV-2 antibody responses after infection or vaccination. However, collection of these samples is invasive and requires trained personnel and equipment for immediate processing. Once collected, plasma and sera must be stored and shipped at cold temperatures. To define the risk of emerging SARS-CoV-2 variants and the longevity of immune responses to natural infection and vaccination, it will be necessary to measure various antibody features in populations around the world, including in resource-limited areas. A sampling method that is compatible with these settings and is suitable for a variety of SARSCoV-2 antibody assays is therefore needed to continue to understand and curb the COVID-19 pandemic.

KEYWORDS dried blood spot, SARS-CoV-2, COVID-19, antibodies, antibody binding, neutralizing antibody, phage display, epitope mapping, neutralizing antibodies

rathe he ability to detect and characterize antibodies targeting severe acute respiratory syndrome coronavirus 2 (SARS-CoV-2) proteins in plasma has been one of the most informative tools during the ongoing COVID-19 pandemic. Serological testing identifies cases of previous infection, including those not revealed by symptoms and viral testing, and therefore provides a more accurate estimate of regional exposure rates than cumulative reverse transcription-PCR (RT-PCR)-based testing (1). In addition to public health surveillance, assessing SARS-CoV-2 antibody binding and functional

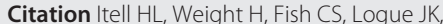
Franko N, Wolf CR, McCulloch DJ, Galloway J, Matsen FA, IV, Chu HY, Overbaugh J. 2021 SARS-CoV-2 antibody binding and neutralization in dried blood spot eluates and paired plasma. Microbiol Spectr 9:e01298-21. https://doi.org/10.1128/Spectrum.01298-21. Editor Heba H. Mostafa, Johns Hopkins Hospital

Copyright $\odot 2021$ Itell et al. This is an openaccess article distributed under the terms of the Creative Commons Attribution 4.0 International license.

Address correspondence to Helen Y. Chu helenchu@uw.edu, or Julie Overbaugh, joverbau@fredhutch.org.

Received 16 August 2021

Accepted 17 September 2021

Published 20 October 2021 
activity has provided insight into the magnitude, features, and durability of antibody responses elicited by natural infection (2-4) and, more recently, vaccination (5-7). Antibody-based investigations have therefore informed lockdown regulations, vaccine development (8-11), possible correlates of protection $(4,12,13)$, and more.

Though tremendous progress has been made to curb the pandemic, several pressing questions remain that necessitate the continued evaluation of SARS-CoV-2 antibodies in large cohorts around the world. Namely, it is unknown how long immunity conferred by infection or vaccination lasts and whether these forms of immunity are protective against viral variants. Addressing these questions will likely require global sample collection for years to come, as immunity against variants must be investigated as they emerge and there is an ever-growing list of vaccines $(8-11,14)$, second dose combinations (15), and boosters (16) that must be evaluated for longevity of protection.

The enormity of this task underscores the need to optimize the feasibility and practicality of SARS-CoV-2 antibody investigations. Some of the most expensive and timeconsuming aspects of these studies involve the collection, shipping, and storage of plasma and serum samples. These sample types are collected via venipuncture by trained phlebotomists typically in the clinic and are immediately stored in a refrigerator or freezer and longer term at $-20^{\circ} \mathrm{C}$. The cold chain must be maintained during transportation for biospecimen integrity. Therefore, if individuals cannot access a clinic, phlebotomists are unavailable or overburdened, the cold chain is not maintained, or long-term $-20^{\circ} \mathrm{C}$ storage is too costly, using plasma and/or serum sampling becomes logistically prohibitive.

Dried blood spots (DBS) have previously been used for nucleic acid and antibody testing and represent a more practical sampling type for SARS-CoV-2 antibody studies. DBS cards are prepared by spotting whole blood onto filter paper cards. Once dried, cards are stable at ambient temperature for at least a few weeks $(17,18)$ and can be mailed without a cold chain or special authorizations for international shipments (19). DBS cards can therefore be collected at home via a noninvasive, self-administered fingerstick and mailed to the laboratory, where small DBS discs are excised and eluted for assay use (20). DBS cards bypass the need for trained personnel for collection or the cold chain for shipping, which not only lowers costs and reduces frontline worker demand, but also facilitates sampling hard-to-reach populations.

The utility and reliability of DBS cards have been demonstrated for several decades. DBS sampling has been used for infant metabolic screening since the 1960s $(21,22)$ and now has broad applications, with over 2,000 analytes measured in DBS eluates to date (23). In the context of infectious disease research, DBS cards are valuable for the surveillance and study of HIV and tropical diseases (24-26) by enabling sampling in resource-limited areas. Therefore, when the current pandemic began, several groups sought to verify the use of DBS eluates for SARS-CoV-2 antibody assays. The most robust of these studies compared antibody binding measurements between paired DBS eluates and plasma or sera from COVID-19 convalescent individuals (27-36), and, impressively, all have found strong agreement between sample types. Despite this supportive evidence, the majority of these reports did not use self-collected, mailed-in fingerstick DBS cards and the compatibility of DBS with other assay formats, including neutralization, has not been carefully examined for SARS-CoV-2.

In this study, we addressed gaps in the SARS-CoV-2 DBS field by collecting paired plasma and DBS cards from COVID-19 convalescent and SARS-CoV-2-vaccinated individuals. We assessed the agreement between sample types for several antibody-based methods, including a widely used receptor-binding domain (RBD) enzyme-linked immunosorbent assay (ELISA) (37, 38), a comprehensive phage display approach (39), and a SARS-CoV-2 spike neutralization assay (40), which we optimized here for higher throughput. For all approaches, we found consistently high agreement between sample types, including between paired plasma and eluates from self-collected fingerstick DBS cards. Additionally, we evaluated the stability of antibodies on DBS cards after 6 months at room temperature (RT) and found no substantial decline in SARS-CoV-2-specific lgG binding. These results support the adoption 


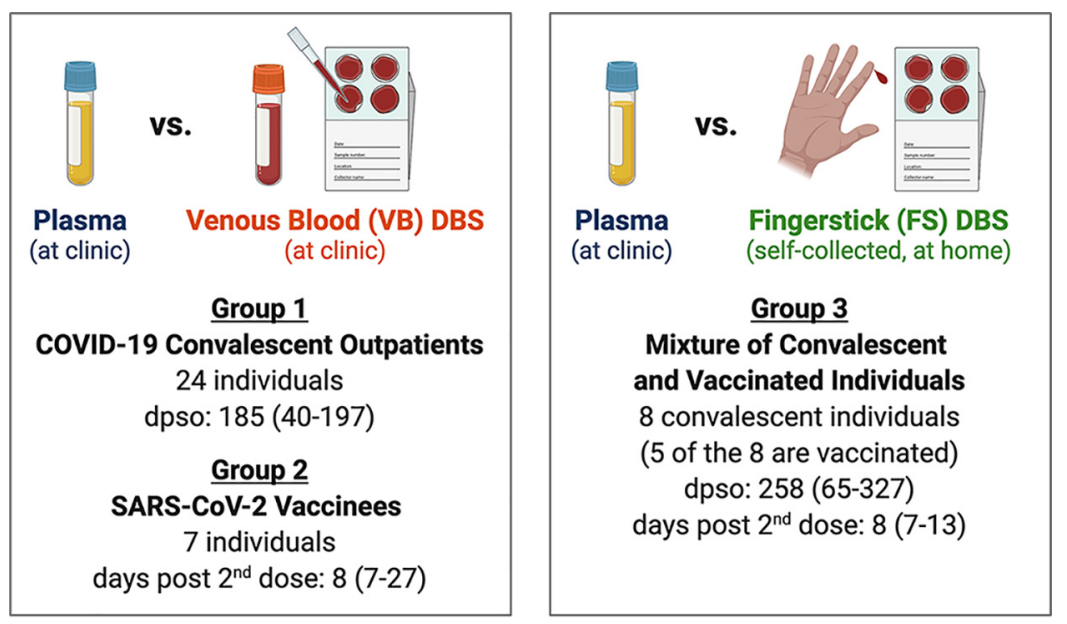

FIG 1 Characteristics of paired sample groups. Paired samples were assigned to one of three study groups based on the sample types collected and participant SARS-CoV-2 infection and vaccination history as outlined in the figure. All vaccinated individuals received two doses of the Moderna mRNA1273 or Pfizer/BioNTech BNT162b2 vaccines. Values are shown as median (with range in parentheses). dpso, days post-symptom onset. The figure was created with BioRender.com.

of DBS sampling for SARS-CoV-2 antibody studies as a reliable, feasible addition to current plasma and serum approaches.

\section{RESULTS}

Characteristics of paired sample groups. Individuals with previous COVID-19 infection and/or SARS-CoV-2 vaccination were enrolled into a prospective observational study at the University of Washington-Seattle, and paired plasma and DBS cards were collected from these individuals. DBS cards were self-prepared at home via fingerstick (FS DBS) or at the clinic by spotting venous blood onto cards immediately after venipuncture (VB DBS). Paired samples were designated into one of three sample groups depending on DBS type and history of infection and/or vaccination, as outlined in Fig. 1.

VB DBS eluates reflect total and SARS-CoV-2-specific IgG levels in paired plasma from COVID-19 convalescent patients. We first measured total lgG levels in group 1 VB DBS eluates and paired plasma $(n=24)$ to estimate the volume of plasma on each 6-mm DBS subpunch. IgG concentrations determined by ELISA ranged from 110 to $317 \mu \mathrm{g} / \mathrm{ml}$ in VB DBS samples eluted in $100 \mu \mathrm{l}$ of phosphate-buffered saline-Tween (PBS-T) (Fig. 2A), which indicates that a median of $17.9 \mu \mathrm{g}$ lgG was eluted from each disc. By comparing the IgG amount on each VB DBS disc to the levels in paired plasma, we calculated that each 6-mm disc from group 1 contains a median of $5.6 \mu \mathrm{l}$ of plasma (range, 4.2 to $7.9 \mu \mathrm{l}$ ). Therefore, there is an approximate 20 -fold initial plasma dilution introduced when DBS discs are eluted that must be accounted for in downstream assays. Overall, there was a strong correlation in lgG levels measured between these two sample types (Pearson's $R=0.83$ ) (Fig. 2A).

To determine whether VB DBS-eluted antibodies recapitulate plasma SARS-CoV-2 RBD binding, we assayed samples via a widely used in-house RBD ELISA $(37,38)$. At point dilutions that accounted for the initial $\sim 20$-fold dilution introduced during DBS preparation, paired samples demonstrated very similar RBD optical density (OD) measurements (median fold change of 1) (Fig. 2B). Similarly, the trends in binding magnitude across individuals strongly agreed between sample types (Pearson $R=0.98$ ) (Fig. 2B). These results demonstrate the sensitivity of DBS eluates to detect antibody binding despite the dilution that occurs due to sample processing. We further assessed eluate and plasma agreement by performing Bland-Altman analysis on the absolute difference between the OD measurements for each sample type (Fig. 2B). We observed an average bias of $+0.031 \mathrm{OD}$ in plasma (95\% confidence interval $[\mathrm{Cl}],-0.104$ to 0.166 ) and only one sample pair, which also had the highest average OD, exceeded the 
Total IgG ELISA
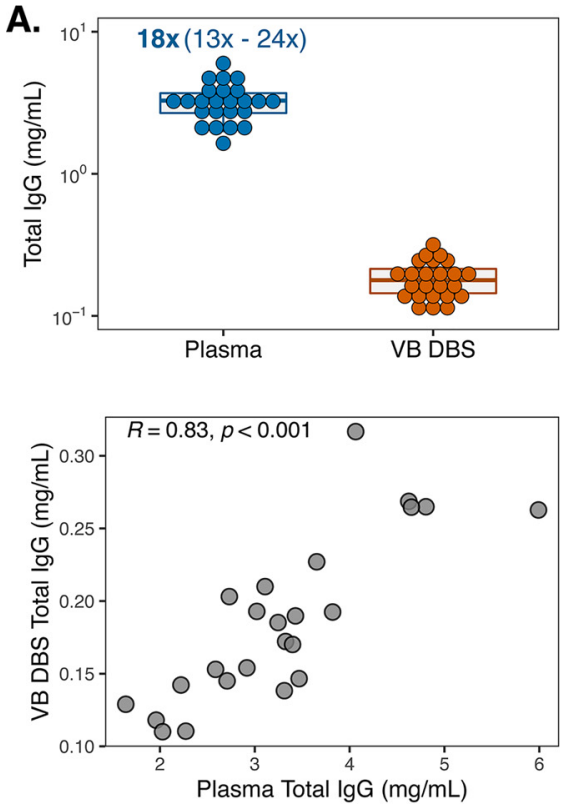

SARS-CoV-2 RBD ELISA
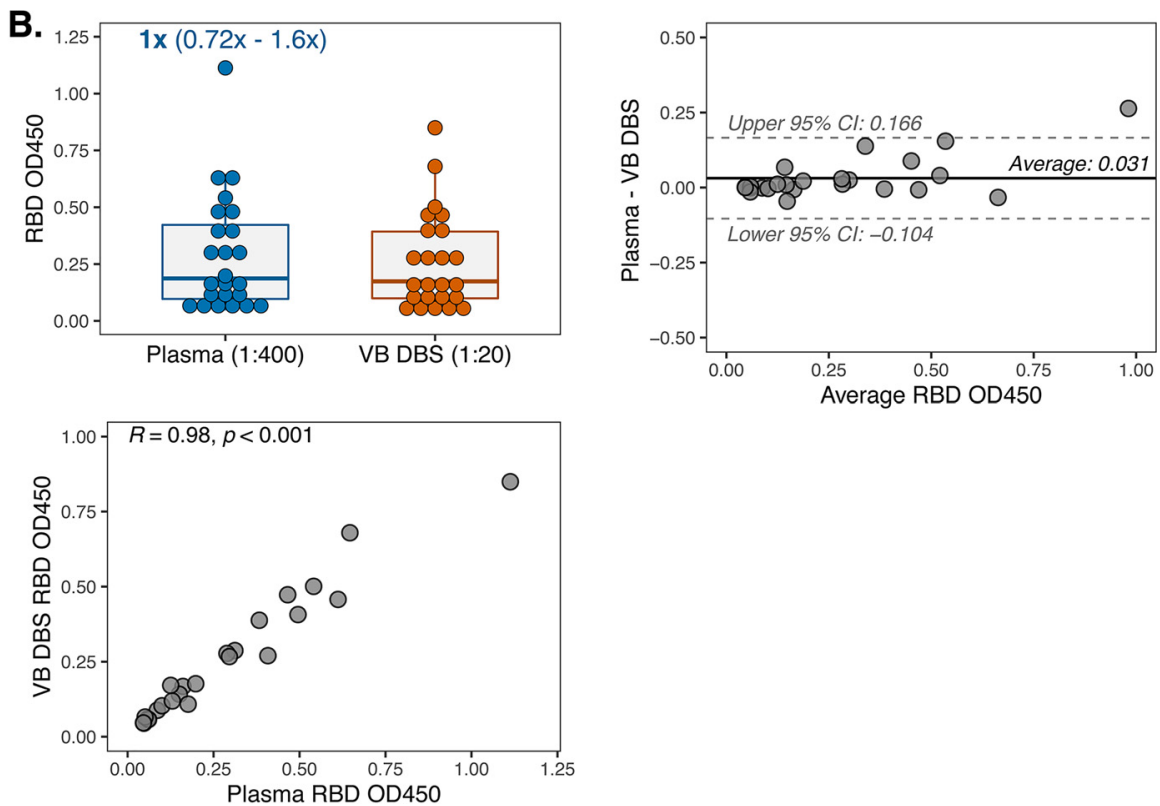

FIG 2 VB DBS eluates reflect total and SARS-CoV-2-specific IgG levels in paired plasma from COVID-19 convalescent patients. (A) Total IgG concentrations in group 1 VB DBS eluates and paired plasma ( $n=24$ pairs) and the Pearson $R$ correlation comparing IgG levels between sample types. The median and range fold differences between paired samples are reported above the plasma data. (B) lgG reactivity to SARS-CoV-2 RBD protein at single dilutions, as indicated. Results were also depicted as a Pearson $R$ correlation and a Bland-Altman plot to compare VB DBS eluate and plasma RBD OD ${ }_{450}$ measurements.

95\% Cls. This average bias falls below the typical level of background observed in empty RBD ELISA wells (0.05 OD unit [data not shown]). Therefore, we found high concordance in SARS-CoV-2 RBD binding via a standard ELISA between paired VB DBS eluates and plasma from convalescent individuals.

Polyclonal antibody response characteristics and epitope specificities can be defined using DBS. We next sought to examine the utility of DBS to capture epitope specificity and to determine whether antibodies to the dominant SARS-CoV-2 epitopes present in polyclonal plasma are preserved in VB DBS eluates. To address this, we tested 22 sample pairs from group 1 for binding to a library of phage displaying SARS-CoV-2 peptides. This phage library expresses 39-amino-acid-long peptides that span the entire SARS-CoV-2 proteome in 20-amino-acid increments, for a total of 480 SARS-CoV-2 peptides (39). Ten micrograms of IgG for each sample was incubated with the peptide library. Antibody-phage complexes were then immunoprecipitated and sequenced to define the linear peptides that antibodies bound to in the two sample types.

In agreement with a previous report from our group on convalescent plasma (39), the proteins with the highest magnitude of peptide binding as measured by counts per million (CPM) were ORF1ab, nucleocapsid, and spike for both sample types. Within these dominant sites, VB DBS eluates closely recapitulated the binding profiles observed in plasma on a cohort-wide scale (Fig. 3A). Moreover, average CPM for each SARS-CoV-2 peptide across the 22 individuals strongly correlated between sample types (Pearson $R=0.87$ ) (Fig. 3B), indicating cohort-wide agreement across all proteins. To contextualize the magnitude of this correlation, we compared average CPM across the 22 plasma samples between duplicate assay wells and observed a very similar level of agreement (Pearson $R=0.94$ [data not shown]), suggesting that antibodies eluted from DBS cards recapitulate cohort-wide plasma epitope profiling results nearly to the level of within-assay plasma replicates.

We also compared epitope profiles between VB DBS eluates and plasma on the individual level by correlating SARS-CoV-2 peptide CPM results between sample pairs. We observed strong agreement between sample pairs with a median Pearson $R$ coefficient of 0.82 and $17 / 22$ pairs having Pearson $R$ values greater than 0.5 (Fig. 3C). To evaluate whether sample data quality influences agreement between paired samples, we 

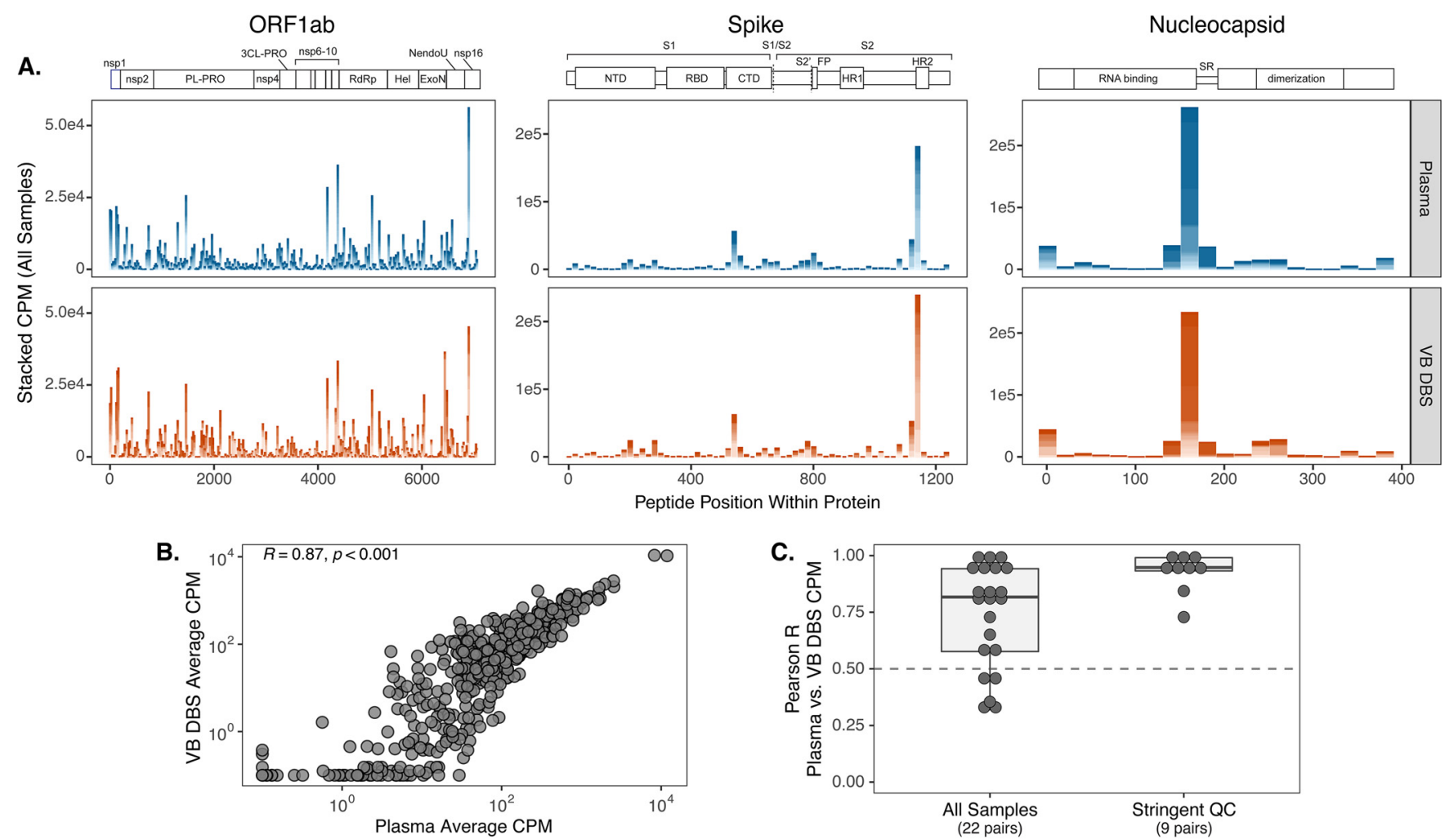

FIG 3 Polyclonal antibody response characteristics and epitope specificities can be defined using DBS. (A) Counts per million (CPM) of SARS-CoV-2 peptides within the three proteins with the highest magnitude of binding: ORF1ab, spike, and nucleocapsid. Peptide CPM are stacked across group 1 individuals for each sample type $(n=22)$. (B) Pearson $R$ correlation of average peptide CPM between sample types. (C) CPM values between sample pairs were correlated for each individual, and the distribution of correlation coefficients is shown for all sample pairs and those with high replicate reproducibility. QC, quality control.

correlated SARS-CoV-2 peptide CPM values between duplicate assay wells and focused on those sample pairs with high DBS replicate agreement (replicate Pearson $R>0.5$; $n=9$ pairs). Peptide counts between the resulting plasma and VB DBS pairs were consistently highly correlated (median Pearson $R=0.95$ ) (Fig. $3 C$ ), which suggests that DBS eluates more closely reflect paired plasma results when DBS replicate reproducibility is high. These data support the use of VB DBS eluates in place of plasma for both cohort-wide epitope-mapping investigations and for the evaluation of individual binding profiles.

Neutralizing antibody levels in vaccinated individuals can be accurately measured using DBS. Recent studies continue to support antibody-mediated neutralization of SARS-CoV-2 as an important immune response conferring protection against infection and COVID-19 disease $(12,13,41)$. Therefore, there is a continued need to evaluate levels of neutralization in large cohorts not only to understand the duration of this response after vaccination but also to assess neutralization efficacy against emerging viral variants. To determine whether DBS eluates capture plasma neutralization activity, we collected paired plasma and VB DBS cards from seven individuals at a median of 8 days after their second Moderna mRNA-1273 or Pfizer/BioNTech BNT162b2 SARS-CoV-2 vaccination (group 2 in Fig. 1). For this experiment, DBS discs were eluted in $50 \mu \mathrm{l}$ serum-free medium instead of $100 \mu$ l PBS-Tween to concentrate the eluate and ensure its compatibility with cell culture (see Materials and Methods). We first measured total IgG levels in these concentrated, media-eluted VB DBS eluates and paired plasma and observed a median 8-fold difference between sample types (Fig. 4A). This was approximately half of that observed with VB DBS eluates eluted in twice the volume (Fig. 2A) and corresponded with a median of $6.3 \mu$ l plasma per 6-mm disc, which was very similar to the prediction from the larger elution volume. Consistent with the total IgG results with group 1 samples, group 2 VB DBS eluates and plasma IgG levels strongly correlated (Pearson $R=0.91$ ) (Fig. 4A). 
Total IgG ELISA
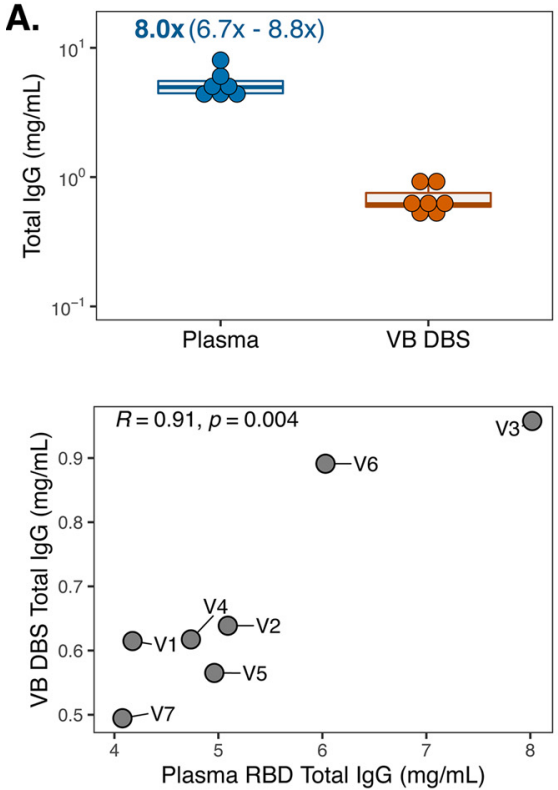

SARS-CoV-2 Spike Neuts (96-WP)
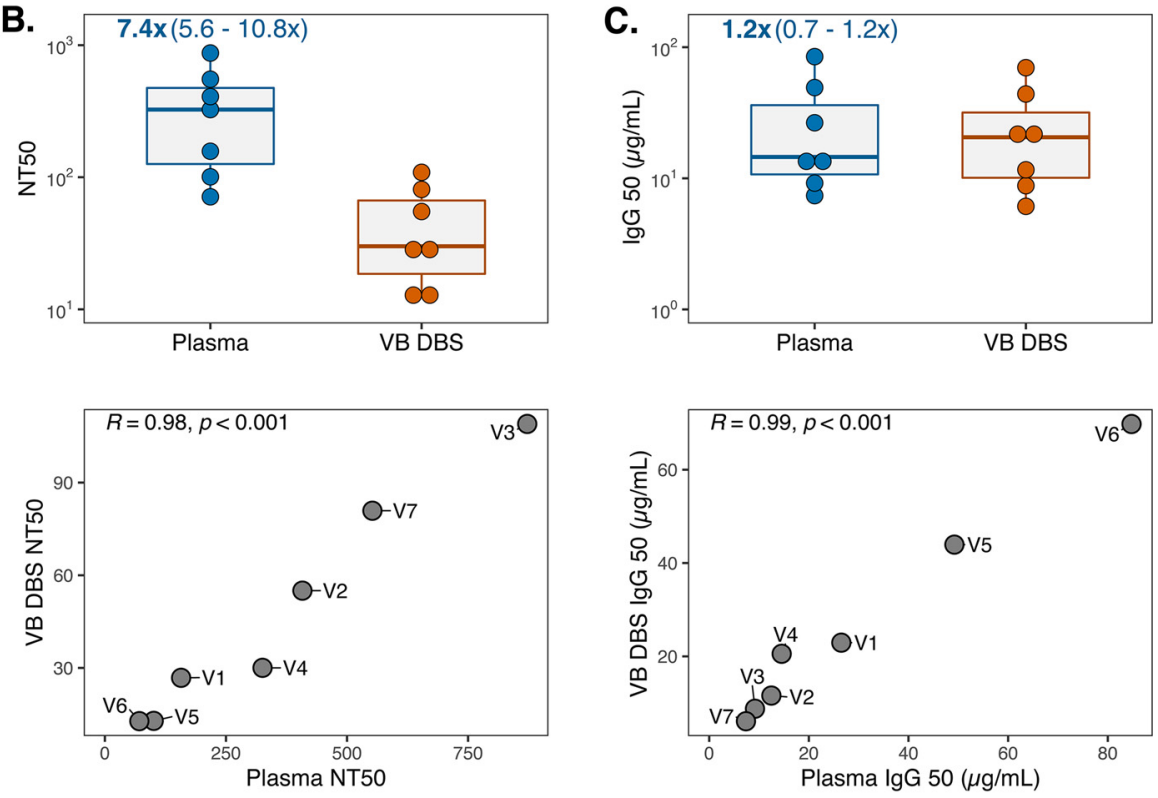

FIG 4 Neutralizing antibody levels in vaccinated individuals can be accurately measured using DBS. (A) Total lgG levels in concentrated, medium-eluted group 2 VB DBS eluates and paired plasma ( $n=7$ pairs) and respective Pearson $R$ correlations between sample types. Data points in the correlation plot are labeled with group 2 participant IDs (V1 to V7). (B) Fifty percent neutralization titer ( $\mathrm{NT}_{50}$ ) and (C) IgG $\mathrm{Ig}_{50}$ (total $\mathrm{IgG}_{\mathrm{g}}$ concentration divided by $\mathrm{NT}_{50}$ ) results for sample type pairs and Pearson $R$ correlations. Neuts, neutralization assays.

To evaluate neutralization activity in plasma and DBS eluates, we leveraged a previously described SARS-CoV-2 spike-pseudotyped lentiviral particle assay (40) and found that all plasma samples from vaccinated individuals had detectable $50 \%$ neutralization titers $\left(\mathrm{NT}_{50}\right.$; range, 71.1 to 872.1). VB DBS eluates demonstrated neutralization titers 7.4-fold lower than those of plasma (Fig. 4B), which is consistent with the 8-fold difference in total lgG levels (Fig. 4A). Remarkably, the $\mathrm{NT}_{50}$ values between sample types correlated very strongly (Pearson $R=0.98$ ) (Fig. 4B). To understand whether the 7.4-fold difference in $\mathrm{NT}_{50}$ values between sample types was driven by differences in total lgG content, we calculated the $\lg _{50}$ for each sample $\left(\operatorname{lgG}_{50}=\lg G\right.$ concentration/ $\left./ \mathrm{NT}_{50}\right)$. After this normalization, there was no significant difference in neutralization activity between sample types (Wilcoxon rank $P$ value $=0.22$, fold difference $=1.2$ ) (Fig. 4C), and the strong correlation between sample pairs was maintained (Pearson $R=0.99$ ) (Fig. 4C). Importantly, these results were not impacted by background signal from either sample type, as a prepandemic serum pool and an eluate from a blank DBS card did not yield any neutralization activity (see Fig. S1 in the supplemental material).

These findings indicate that antibodies eluted from DBS cards recapitulate plasma $\mathrm{NT}_{50}$ trends and $\operatorname{lgG}_{50}$ magnitude. However, a drawback of the spike neutralization assay is that it requires large sample volumes due to its 96-well-plate (96-WP) layout, which could be limiting in the case of DBS sampling. We therefore adapted the existing SARS-CoV-2 spike neutralization assay to a high-throughput 384-WP format, which uses a third of the sample volume and assays five times the number of samples per plate. To compare assay formats, we reassayed the same seven sample pairs and found that $\mathrm{NT}_{50}$ measurements strongly correlated between plates for both sample types, which demonstrates that trends in neutralization titers across samples and sample types are maintained in the 384-WP format (Pearson $R=0.95$ ) (Fig. 5A). Additionally, as we observed in the 96-WP assay, $\mathrm{NT}_{50}$ and $\operatorname{lgG}_{50}$ values were strongly correlated between sample types in the high-throughput format (Fig. 5B and C). The 384-WP spike neutralization assay is thus a suitable and more practical alternative to the traditional 96-WP format for both DBS eluates and plasma.

Consistent levels of antibody recovery from DBS cards stored at room temperature for 6 months. One of the main advantages of DBS sampling is that DBS cards do not require a cold chain for collection, transportation, or storage. To evaluate the stability 


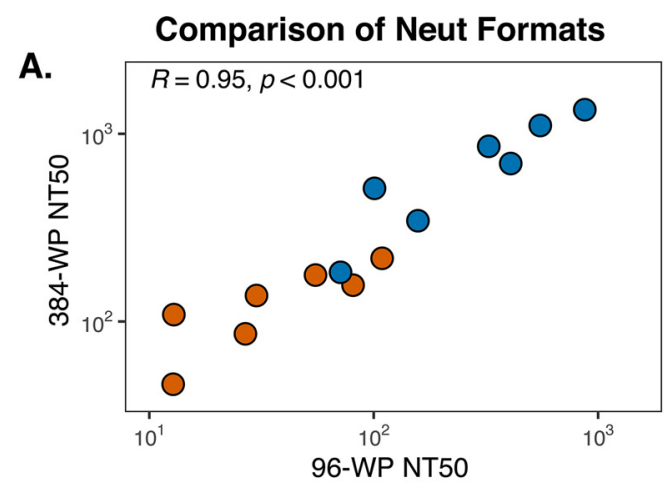

SARS-CoV-2 Spike Neuts (384-WP)
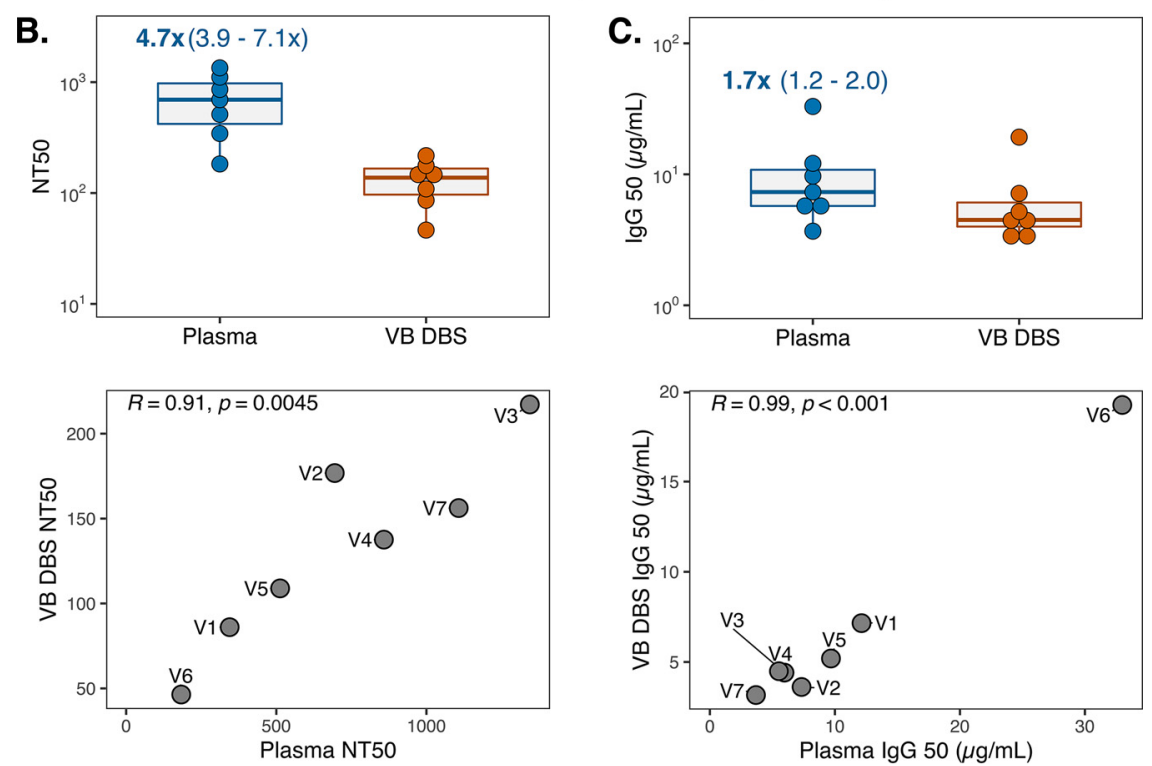

FIG 5 SARS-CoV-2 spike neutralization can be reliably detected in a high-throughput 384-well-plate (WP) format. (A) Pearson $R$ correlation of $\mathrm{NT}_{50}$ measurements for group 2 plasma samples (blue) and VB DBS eluates (orange) as determined by 96-WP and 384WP neutralization (Neut) assays. (B) $\mathrm{NT}_{50}$ and (C) $\operatorname{lgG}_{50}$ results for sample type pairs and Pearson $R$ correlations in the $384-W P$ format. Data points in the correlation plots are labeled with group 2 participant IDs (V1 to V7). Neuts, neutralization assays.

of antibodies on DBS cards after prolonged storage without refrigeration or freezing, we measured total IgG and SARS-CoV-2 RBD IgG binding in eluates from group 1 VB DBS cards after 1 week, 6 weeks, and 6 months of room temperature storage (Fig. 6). DBS cards were kept in the dark in individual plastic bags with desiccant packets during this time, which is standard practice as humidity and UV light are known to damage DBS (18). Total IgG recovered from DBS was similar at 6 months to that at 1 week post-collection, and levels were highly correlated (Pearson $R=0.91$ ). Likewise, SARSCoV-2 RBD binding was consistent over this period (Pearson $R=0.97$ ), demonstrating that antibodies are preserved on DBS cards stored at room temperature for at least 6 months.

IgG binding and neutralization activity are highly correlated for self-collected FS DBS and plasma. The DBS cards used so far in this study were prepared with venous blood, similar to prior studies $(27,30,42-44)$, and were thus informative intermediates to understand antibody features that can be captured and preserved on filter paper. However, the ideal DBS sample for broad field application would be fingerstick DBS cards (FS DBS) self-collected by individuals at home and mailed to the clinic for storage, processing, and evaluation. To determine whether FS DBS eluates also generate results that reflect plasma, we collected plasma from eight individuals with prior SARS-CoV-2 infection, some of whom were also vaccinated against SARS-CoV-2 (5/8 
Total IgG ELISA
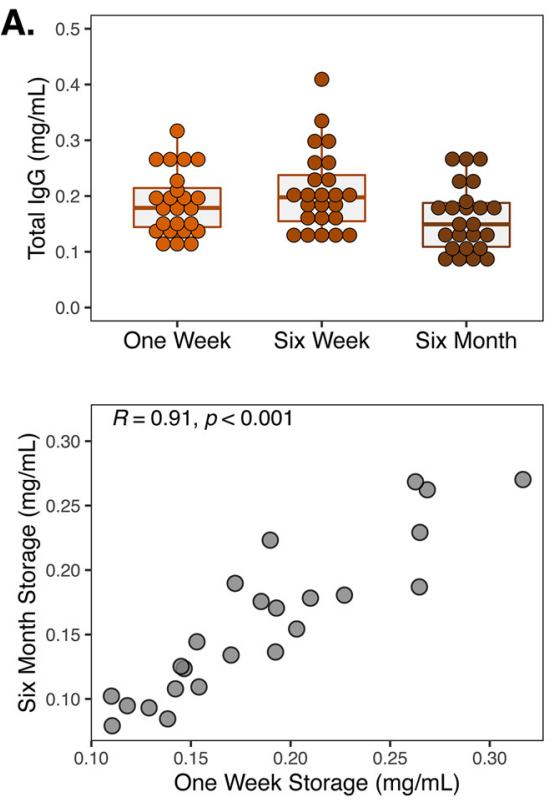

SARS-CoV-2 RBD ELISA
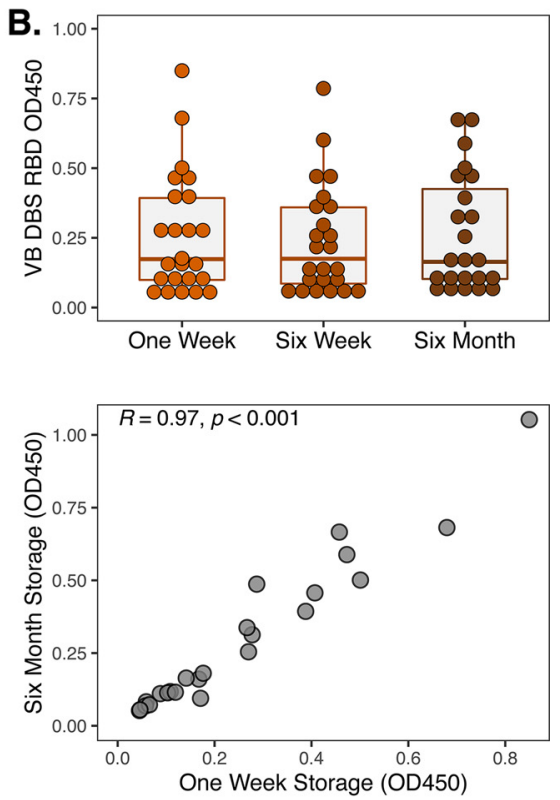

FIG 6 Consistent levels of antibody recovery from DBS cards stored at room temperature for 6 months. (A) Total and (B) RBDspecific IgG levels in eluates from group 1 VB DBS cards $(n=24)$ stored at room temperature for 1 week, 6 weeks, and 6 months. Pearson $R$ correlation values for comparison between lgG levels measured after storage for 1 week and for 6 months are also depicted.

individuals [group 3 in Fig. 1]). During their clinic visit for plasma collection, individuals were provided with a kit for FS DBS card preparation (see Fig. S2 in the supplemental material) and were instructed to fill out the card on the same day, dry it for $3 \mathrm{~h}$, and mail it back to the clinic.

Like VB DBS samples, eluates from group 3 FS DBS cards recapitulated total IgG trends observed in paired plasma (Pearson $R=0.92$ ) (Fig. 7A). We then measured RBD IgG binding in these samples, accounting for the 10-fold difference in IgG levels between sample types. As expected, there was no difference in the magnitude of RBD IgG OD measurements (Fig. 7B). These results were perfectly correlated between sample types (Pearson $R=1$ ) and only demonstrated a mean bias of 0.024 OD unit. In this data set, we noticed that sample RBD binding was bimodally distributed for both sample types. This difference was driven by vaccination status, as the five individuals with detectable RBD binding all previously received SARS-CoV-2 vaccines, whereas participants F1, F4, and F8 had not.

Finally, we assessed spike neutralization activity in two group 3 participants (F2 and F5) who demonstrated high RBD binding and had enough DBS discs remaining. Though this sample size was low, the shapes of the neutralization curves were very similar between sample types (Fig. $7 \mathrm{C}$ ), and the trend in $\mathrm{NT}_{50}$ values was maintained, with participant $\mathrm{F} 2$ having slightly higher $\mathrm{NT}_{50}$ than $\mathrm{F} 5$. Ig $\mathrm{G}_{50}$ levels were also very similar for these two sample pairs, which suggests that FS DBS, like VB DBS, accurately reflect plasma neutralization activity.

\section{DISCUSSION}

DBS sampling overcomes the logistical barriers of plasma collection because the cards can be self-collected by fingerstick and mailed to the laboratory at ambient temperature, where they are eluted for antibody assays. For SARS-CoV-2 studies, adoption of DBS may reduce frontline worker demand, improve sampling in resource-limited areas, and increase study enrollment. Though prior work with DBS and plasma pairs has supported the suitability of DBS for SARS-CoV-2 antibody binding assays (27-36), important gaps remained that prevented the broad implementation of this sample 
Total IgG ELISA
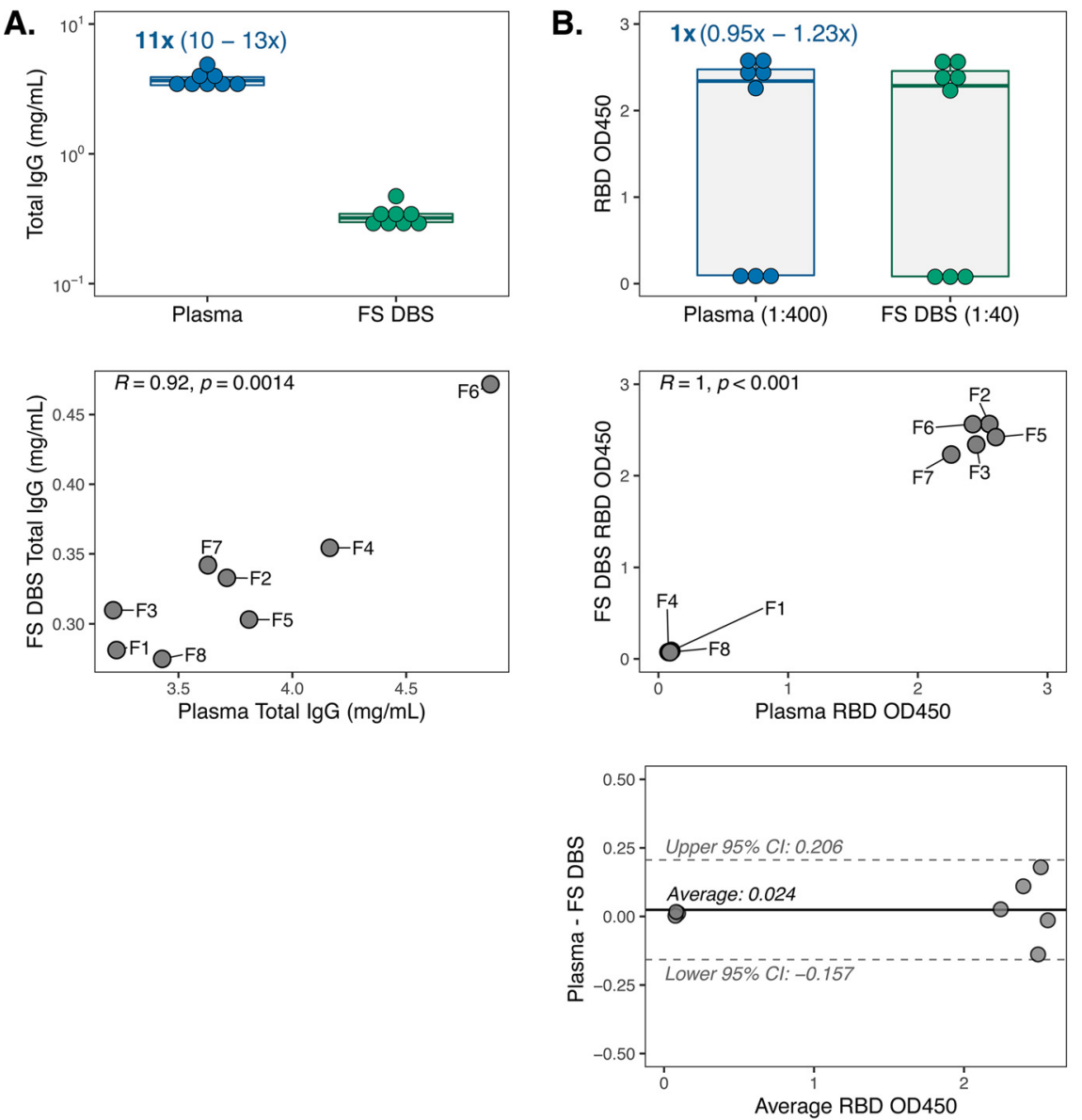

\section{SARS-CoV-2 Spike Neuts (96-WP)}
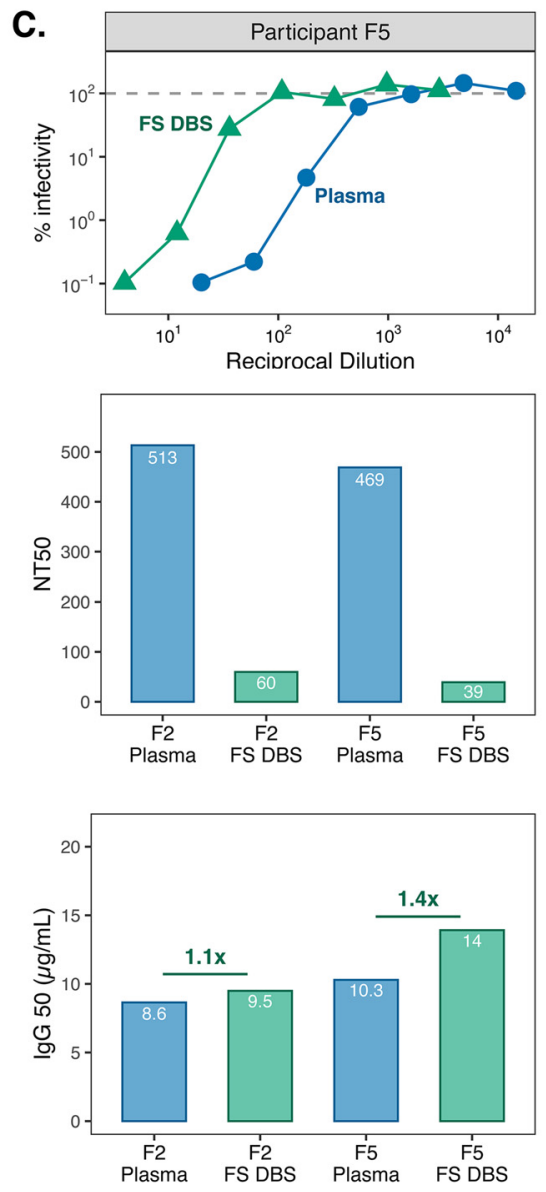

FIG 7 lgG binding and neutralization activity are highly correlated for self-collected FS DBS and plasma. (A) Total IgG concentrations and (B) RBD binding levels in group 3 paired sample types ( $n=8$ pairs) with respective Pearson $R$ correlations and Bland-Altman plot analyses. Data points in the correlation plots are labeled with group 3 participant IDs (F1 to F8). (C) Neutralization curves against SARS-CoV-2 spike pseudovirus by plasma and FS DBS eluate from participant F5, as well as $\mathrm{NT}_{50}$ and $\operatorname{lgG}_{50}$ results for paired sample types from participants $\mathrm{F} 2$ and F5. Neuts, neutralization assays.

type. For example, most studies used DBS with venous $(27,30)$ or fingerstick blood collected at the clinic with the assistance of a phlebotomist $(29,31-33,35)$, which does not account for variables introduced with self-sampling or ambient shipping. One study did utilize self-collected fingerstick cards (28), but only evaluated four sample pairs via an agglutination-PCR assay. Finally, all prior reports evaluated antibody binding in COVID-19 convalescent DBS samples. As vaccine distribution continues to expand and evidence grows for neutralization being an important correlate of protection $(12,13,41)$, it is critical that DBS eluates also recapitulate SARS-CoV-2 neutralization activity in vaccinated individuals.

In this study, we build on previous findings that supported DBS for antibody binding by collecting and testing paired DBS and plasma from 39 individuals across a range of assays, including epitope profiling and spike neutralization assays. We evaluated not only convalescent samples but also samples from vaccinees and fingerstick DBS cards self-collected at home. The work reported here thus extends the utility of DBS sampling to ultimately support the adoption of DBS for SARS-CoV-2 antibody studies.

Prior studies often elute DBS discs in volumes that prepare samples directly for testing in a single assay format $(27,29,31,32,34,36)$. Because we sought to employ DBS for various assays, we first measured total lgG levels in DBS eluate and plasma pairs to estimate the volume of plasma extracted from each disc, to ultimately inform sample dilutions and data normalization approaches. Based on the total IgG results from all 39 sample pairs, we calculated that a median of $6.1 \mu \mathrm{l}$ plasma was eluted from each 
6-mm DBS subpunch. This estimate agrees with a report that compared spotted blood volume to DBS area and determined that $6-\mathrm{mm}$ punches contain 5.8 to $6.4 \mu \mathrm{l}$ plasma (27). When we accounted for the dilution factor introduced by eluting the $6.1 \mu \mathrm{l}$ plasma from each disc into larger volumes, we found that DBS eluates recapitulated not only the trends but also the binding magnitude of paired plasma for binding and neutralization assays. These findings demonstrate that plasma and total IgG content on DBS discs can be accounted for during DBS elution, sample dilution, and/or data analysis to ensure assay sensitivity and facilitate direct comparisons between plasma and DBS results. Detection sensitivity in DBS is thus likely only compromised for assays that require undilute plasma or very large sample volumes, for which the difference in total IgG content cannot be adjusted.

Our study and prior reports demonstrate strong agreement between paired plasma and DBS for single-epitope SARS-CoV-2 binding assays, such as the commonly used RBD ELISA. However, several epitopes need to be interrogated to elucidate immunodominant proteins or the effects of variant mutations. Phage display libraries enable multiepitope investigations by providing high-throughput assessment of binding to linear peptides (45). To determine whether DBS reflect the polyclonal specificities that exist in plasma, we assayed paired samples from 22 convalescent individuals against a recently reported phage library that spans the SARS-CoV-2 proteome (39). DBS eluates identified the same immunodominant proteins as plasma and reflected plasma epitope profiles on both the cohort level and for individual participants. Individual-level agreement between plasma and DBS was further improved by only considering samples with high reproducibility between replicates, suggesting that replicate experiments may provide the best accuracy.

We also evaluated the performance of DBS in SARS-CoV-2 pseudovirus neutralization assays - the traditional 96-WP format and a new high-throughput 384-WP adaptation. In the 96-WP version, DBS replicated trends in plasma $\mathrm{NT}_{50}$ results and matched plasma $\operatorname{lgG}_{50}$ levels, demonstrating for the first time that plasma neutralization against SARS-CoV2 spike is preserved on DBS cards. While these findings are encouraging, the 96-WP neutralization assay is not ideal for testing DBS eluates or precious plasma specimens due to large sample volume requirements. We therefore established a 384-WP format for the assessment of both plasma and DBS eluates that uses a third of the sample volume and can assay five times the number of samples per plate. The $\mathrm{NT}_{50}$ results strongly correlated between assay formats, and the agreement between DBS and plasma was maintained. The 384-WP SARS-CoV-2 spike neutralization assay is thus a sample-sparing, highthroughput approach for the evaluation of plasma and DBS eluates.

Our study ultimately provides evidence that SARS-CoV-2 antibody binding and neutralization are detectable in eluates from DBS cards, including those prepared at home by fingerstick and mailed to the clinic, at levels that reflect paired plasma. This work supports the implementation of DBS sampling for SARS-CoV-2 antibody investigations as a more practical alternative to plasma and serum collection, particularly in resourcelimited settings.

\section{MATERIALS AND METHODS}

Study participants. Paired DBS and plasma specimens were collected from COVID-19 convalescent and SARS-CoV-2-vaccinated individuals enrolled as part of the Hospitalized or Ambulatory Adults with Respiratory Viral Infections (HAARVI) research study in Seattle, WA. All participants completed informed consent as approved by the University of Washington Institutional Review Board (protocol no. STUDY00000959). Paired samples from 39 HAARVI participants were collected between September 2020 and February 2021 and were categorized into three sample groups for this study depending on the individual's SARS-CoV-2 infection and vaccination history and the specimen types collected (Fig. 1). Group 1 consisted of 24 convalescent individuals with paired plasma and VB DBS cards. Group 2 included seven vaccinated participants with paired plasma and VB DBS cards. Finally, group 3 was comprised of eight convalescent individuals, five of whom were also vaccinated, with paired plasma and FS DBS cards. Convalescent individuals refer to those with previous PCR-confirmed, symptomatic SARS-CoV-2 infection that did not require hospitalization. Vaccinated participants received two doses of the Moderna mRNA1273 or Pfizer/BioNTech BNT162b2 SARS-CoV-2 vaccine prior to sample collection. 
Plasma and VB DBS sample collection. Venous blood was collected from each participant into acid citrate dextrose (ACD) tubes. For individuals in groups 1 and 2, VB DBS cards were prepared immediately after venipuncture by inverting blood tubes, pipetting $80 \mu$ l onto each circle of a Whatman 903 card (Sigma no. WHA10534612), and drying cards overnight at room temperature (RT). Dried VB DBS cards were stored in a drawer at RT in individual plastic bags containing a desiccant packet (Grainger no. 8 ZF81). All plasma specimens were heat inactivated at $56^{\circ} \mathrm{C}$ for $1 \mathrm{~h}$ prior to short-term storage at $4^{\circ} \mathrm{C}$ or long-term storage at $-80^{\circ} \mathrm{C}$.

At-home FS DBS collection kits. Group 3 participants were provided with FS DBS collection kits and instructions at the time of an in-clinic venous blood draw and were advised to perform FS DBS sampling on the same day. Kits included the following: an instruction pamphlet (Fig. S2), one Whatman 903 card in a plastic bag with a desiccant packet, two lancets, one alcohol prep pad, one 95kPA specimen transport bag, one cardboard box, and one prepaid mailer bag. FS DBS cards were mailed to the laboratory at ambient temperature and were stored at RT under the same conditions as VB DBS cards.

DBS elution. Six-millimeter discs were extracted from saturated portions of VB or FS DBS cards using a biopsy punch (4MD Medical no. MLTX33-36). For FS DBS cards with variable spot sizes, discs were extracted from spots that were at least $6 \mathrm{~mm}$ in diameter to ensure a fully saturated sample. Forceps were used to transfer discs into a sterile 2-ml Eppendorf tube. To prevent cross-contamination, biopsy punches were replaced between cards and forceps were cleaned with $70 \%$ ethanol. PBS-T $(1 \times$ PBS, $0.1 \%$ Tween 20) was added to each tube at a ratio of one disc to $100 \mu \mathrm{l}$ PBS-T unless otherwise noted. Samples were eluted overnight at $4^{\circ} \mathrm{C}$ on a plate shaker with gentle agitation $(70 \mathrm{rpm})$. In the morning, tubes were centrifuged at $10,000 \times g$ for $5 \mathrm{~min}$ at RT to pellet discs and debris. Supernatants were extracted and stored at $4^{\circ} \mathrm{C}$.

Quantification of total IgG concentrations. ELISAs were performed to determine total IgG levels in paired plasma and DBS eluates. Immulon 2HB 96-well plates (Thermo Fisher no. 3455) were coated with 50 $\mu \mathrm{l}$ of $25 \mu \mathrm{g} / \mathrm{ml}$ goat anti-human polyvalent lgGs (Sigma no. 11761) in $0.1 \mathrm{M}$ sodium bicarbonate at $4^{\circ} \mathrm{C}$ overnight. Wells were washed three times with $300 \mu$ l PBS-T using a Tecan plate washer and blocked with $50 \mu \mathrm{l}$ blocking buffer (10\% [wt/vol] nonfat milk and $0.05 \%$ Tween 20 in $1 \times$ PBS) for $1 \mathrm{~h}$ at RT. Plasma and DBS eluates were briefly centrifuged at $10,000 \times g$ for $5 \mathrm{~min}$ at RT to pellet debris. Sample dilutions were then prepared in blocking buffer (1:10,000 for plasma, 1:5,000 for VB DBS, and 1:10,000 for FS DBS). An lgG antibody of known concentration was diluted to $3 \mu \mathrm{g} / \mathrm{ml}$ and was titrated 3-fold across 10 wells to serve as the assay standard. Blocking buffer was washed from assay plates, and $50 \mu \mathrm{l}$ of samples and standards was added to plates in duplicate. After $1 \mathrm{~h}$ at RT, wells were washed three times. Secondary antibody was prepared by diluting goat anti-human IgG-horseradish peroxidase (Sigma no. A0170) to 1:2,500 in blocking buffer $(2.24 \mu \mathrm{g} / \mathrm{ml})$. One hundred microliters was added per well, and plates were incubated at RT for $1 \mathrm{~h}$. After incubation with secondary antibody and three washes, plates were developed with $50 \mu$ l of TMB $\left(3,3^{\prime}, 5,5^{\prime}-\right.$ tetramethylbenzidine) substrate (Thermo Fisher no. 34029) and were quenched with equal volumes of $1 \mathrm{~N}$ sulfuric acid after $10 \mathrm{~min}$. Absorbance was immediately read at $450 \mathrm{~nm}$ on a BioTek Epoch plate reader. Duplicate $\mathrm{OD}_{450}$ measurements were averaged, and IgG concentrations in plasma and DBS eluates were interpolated from the standard curve using the five-parameter logistic equation function in GraphPad Prism 8. Agreement between paired sample lgG concentrations was evaluated by calculating the Pearson correlation coefficient between sample types in RStudio.

Detection of SARS-CoV-2 RBD IgG. A previously described IgG ELISA against SARS-CoV-2 RBD that gained FDA emergency use authorization was adapted to measure RBD binding activity in paired plasma and DBS eluates (38). Immulon 2HB 96-well plates (Thermo Fisher no. 3455) were coated with $50 \mu \mathrm{l} /$ well of $2 \mu \mathrm{g} / \mathrm{ml}$ of SARS-CoV-2 RBD protein diluted in $1 \times$ PBS. The RBD protein used as a coating was a gift from Roland Strong's lab and was produced as previously described (46). After an overnight incubation at $4^{\circ} \mathrm{C}$, plates were washed three times with $300 \mu \mathrm{l}$ PBS-T using a Tecan plate washer and blocked with $200 \mu \mathrm{l} / \mathrm{well}$ of $3 \%(\mathrm{wt} / \mathrm{vol}$ ) nonfat milk in PBS-T for $1 \mathrm{~h}$ at RT. Plasma and DBS eluates were centrifuged at $10,000 \times g$ for $5 \mathrm{~min}$ at RT to pellet debris prior to being diluted in dilution buffer ( $1 \%$ [wt/vol] nonfat milk in PBS-T). The following point dilutions were assessed: 1:400 for participant plasma and negativecontrol normal human serum (Gemini Biosciences no. 100-110, lot H87WOOK), 1:20 for VB DBS eluates, and 1:40 for FS DBS eluates. RBD-specific CR3022 IgG (BEl Resources no. NR-52392) was used as a positive control at $1 \mu \mathrm{g} / \mathrm{ml}$. After the blocking buffer was removed, $100 \mu \mathrm{l}$ of sample dilutions was added in duplicate, and assay plates were incubated for $2 \mathrm{~h}$ at RT. Wells were washed three times with PBS-T, and $50 \mu \mathrm{l}$ of goat anti-human IgG-horseradish peroxidase (Sigma \#A0170) diluted 1:3,000 in dilution buffer $(1.87 \mu \mathrm{g} / \mathrm{ml})$ was added per well. After $1 \mathrm{~h}$ at RT, plates were washed three times with PBS-T. Fifty microliters of TMB substrate (Thermo Fisher no. 34029) per well was used to develop assay plates, and after 5 min, $50 \mu \mathrm{l}$ of $1 \mathrm{~N}$ sulfuric acid was used to stop the reaction. Absorbance was immediately read at $450 \mathrm{~nm}$ on a BioTek Epoch plate reader. Agreement between paired sample RBD $\mathrm{OD}_{450}$ measurements was evaluated by calculating the Pearson correlation coefficient between sample types in RStudio.

Linear epitope mapping via phage display, immunoprecipitation, and Illumina sequencing. Linear CoV epitope profiling of paired plasma and VB DBS eluates was performed directly following a phage display approach previously described in detail by our group (39). Specifically, we employed the same pan-CoV phage library design and construction, IgA and IgG immunoprecipitation, Illumina library preparation, and sequence alignment techniques as the previous report. This pan-CoV phage library displays peptides 39 amino acids in length that tile across $17 \mathrm{CoV}$ protein coding sequences, including the entire SARS-CoV-2-Wuhan-1 proteome (GenBank accession no. MN908947). For epitope-mapping experiments, plasma and VB DBS eluates are added to wells containing the phage library such that each well contains $10 \mu \mathrm{g}$ of total IgG, as estimated by ELISA results. After rotating for $20 \mathrm{~h}$ at $4^{\circ} \mathrm{C}$, phage-antibody complexes were pulled down by immunoprecipitation using a 1:1 ratio of protein $A$ and $G$ Dynabeads 
(Invitrogen no. $10002 \mathrm{D}$ and $10004 \mathrm{D}$ ) and were lysed at $95^{\circ} \mathrm{C}$ for $10 \mathrm{~min}$. Sample-selected library phage DNA was prepared for sequencing on an Illumina MiSeq with 126-bp single-end reads using the methods and primers previously described (47).

Illumina MiSeq Reporter software was used by the by the Fred Hutch Genomics Core to demultiplex peptide epitope-mapping sequencing data and generate fastq files. We then used a Nextflow data processing pipeline to align the demultiplexed sample reads to the reference peptide library in parallel, allowing for up to 2 mismatches. This pipeline builds a Bowtie index from the peptide metadata by converting the metadata to fasta format and feeding it into the bowtie-build command. The low-quality end of the reads is trimmed to $93 \mathrm{bp}$ to match the reference lengths before performing end-to-end alignment and allowing for 0 mismatches. For each sample, we quantified the abundance of each peptide by using samtools-idxstats to count the number of reads mapped to each specific peptide in the reference library. Counts per million (CPM) values were calculated from raw read counts to control for read depth differences between samples. Peptide CPMs were merged into a count matrix organized by unique identifiers for each peptide and sample. The metadata tables were tied with the count matrix into an xarray data set using shared coordinate dimensions of the unique sample and peptide identifiers. We used this data set organization as the starting point for downstream epitope profiling analyses.

Due to the focused nature of this investigation on whether DBS agrees with plasma for SARS-CoV-2 antibody responses, downstream analyses specifically evaluated the 480 SARS-CoV-2 peptides included in the library. The following analyses were performed in R to compare plasma and VB DBS linear epitope profiling results. (i) Pearson correlation coefficients were determined for CPM between within-assay technical replicates to inform data quality. (ii) CPM for within-assay replicates were then averaged, and participant-level agreement between sample types was assessed by comparing CPM for VB DBS and plasma pairs via Pearson correlation. (iii) Cohort-level agreement between sample types was evaluated by calculating the average CPM for each peptide across all plasma or VB DBS samples and determining the Pearson correlation coefficient between sample type averages.

SARS-CoV-2 spike pseudovirus production. Pseudovirus expressing SARS-CoV-2 spike protein was produced, and the titer was determined as previously described (40). HEK293T cells were added to 6-well plates at $5 \times 10^{5}$ cells per well in Dulbecco's modified Eagle's medium (DMEM) supplemented with $10 \%$ fetal bovine serum, $2 \mathrm{mM}$ L-glutamine, and penicillin/streptomycin/amphotericin B (Fungizone). After 16 to $25 \mathrm{~h}$, cells were transfected using FuGENE-6 (Promega no. E2692) with the Luciferase_IRES_ZsGreen backbone, Gag/Pol, Rev, and Tat lentiviral helper plasmids, and a plasmid containing the codon-optimized spike sequence from the Wuhan-Hu-1 strain, which contained a 21-amino-acid deletion at the cytoplasmic tail (also known as HDM-SARS2-Spike-delta21). After $24 \mathrm{~h}$, medium was replaced with fresh supplemented DMEM. Between 50 and $60 \mathrm{~h}$ posttransfection, viral supernatants were collected, filtered through $0.22-\mu \mathrm{m}$ pore Steriflip filters, concentrated using 100-kDa Amicon filters (EMD Millipore no. UFC910024), and stored at $-80^{\circ} \mathrm{C}$. The titer of pseudovirus was determined by seeding 96 -well black-walled plates with $1.25 \times 10^{4}$ HEK293T-ACE2 cells and, after 16 to $24 \mathrm{~h}$, adding $100 \mu \mathrm{l}$ of undiluted viral supernatant per well in duplicate. Viral supernatants were then diluted 2-fold in supplemented DMEM over eight wells. Vesicular stomatitis virus glycoprotein (VSV-G) and no-viral-entry-protein (VEP) positive and negative controls, respectively, were included on each plate and treated the same as spike pseudovirus, except that VSV-G titration started at a 1:10 dilution. After $60 \mathrm{~h}, 100 \mu \mathrm{l}$ per well was removed, and $30 \mu \mathrm{l}$ of Bright-Glo (Promega no. E2620) was added. Relative luciferase units (RLU) were measured on a LUMIstar Omega plate reader (BMG Labtech).

SARS-CoV-2 spike neutralization assays (96-WP and 384-WP). DBS samples were eluted for neutralization assays with $50 \mu \mathrm{l}$ of serum-free supplemented DMEM to ensure their compatibility with cell culture. SARS-CoV-2 spike neutralization assays in the traditional 96-WP format were carried out according to a previous report (40). HEK293T-ACE2 cells were brought to $2.5 \times 10^{5}$ cells $/ \mathrm{ml}$, and 96 -well blackwalled plates were seeded with $50 \mu \mathrm{l}$. Assay plates also contained four wells seeded with HEK293T cells without ACE2 and four wells without any cells as negative controls. After 12 to $16 \mathrm{~h}, 60 \mu \mathrm{l}$ of plasma and DBS dilutions were prepared in a separate round-bottomed 96-WP plate with serum-free supplemented DMEM, due to the fact that DBS were eluted in this medium. Samples were initially diluted 1:20 and 1:4 for plasma and DBS, respectively, and were then diluted 3-fold over seven wells. Duplicate dilution wells were prepared for each sample titration. Spike pseudovirus was then diluted to (3.3 to 5$) \times 10^{5}$ RLU per $\mathrm{ml}$ in supplemented DMEM, and $60 \mu \mathrm{l}$ was mixed with the prepared plasma and DBS titrations. After $1 \mathrm{~h}$ at $37^{\circ} \mathrm{C}, 100 \mu \mathrm{l}$ from the virus/sample wells was transferred to the cell plate. To read the plates, $100 \mu \mathrm{l}$ of medium was removed from each well approximately 52 to $58 \mathrm{~h}$ postinfection, and $30 \mu \mathrm{l}$ of Bright-Glo was added. After $2 \mathrm{~min}$, RLU was measured on a LUMIstar Omega plate reader. Technical replicate RLUs were averaged, and the percentage of infectivity was calculated by dividing sample RLU by the corresponding row's positive-control RLU value, which was from virus plus cells from wells that did not have sample added. The $50 \%$ neutralization titers $\left(\mathrm{NT}_{50}\right)$ were determined using GraphPad Prism 8's inhibitor versus response curve, with top and bottom parameters constrained to 1 and 0 , respectively. Finally, $\lg _{50}$ values were calculated by dividing each sample's total lgG concentration by its $\mathrm{NT}_{50}$. Agreement between paired sample measurements for $\mathrm{NT}_{50}$ and $\operatorname{lgG}_{50}$ values was evaluated by calculating the Pearson correlation coefficient between sample types in RStudio.

Spike neutralization assays were adapted to 384-WPs using the same incubation times, sample dilutions, and reagents as described for the 96-WP assay, but with working volumes reduced to approximately $30 \%$. Briefly, black-walled 384-WPs were seeded with $15 \mu \mathrm{l}$ of HEK293T-ACE2 cells at a concentration of $2.5 \times 10^{5}$ cells $/ \mathrm{ml}$. For negative controls, eight wells were seeded with HEK293T cells that do not express ACE2, and an additional eight wells contained supplemented DMEM only. After 12 to $16 \mathrm{~h}$, sample dilutions were prepared in round-bottomed 96-WPs with a total volume of $36 \mu$ l per well. Spike pseudovirus was diluted to (3.3 to 5$) \times 10^{5} \mathrm{RLU}$ per $\mathrm{ml}$, and $36 \mu \mathrm{l}$ was mixed into sample dilution wells. 
After $1 \mathrm{~h}$ at $37^{\circ} \mathrm{C}, 30 \mu \mathrm{l}$ from each virus/sample well was transferred to two wells on the 384-well assay plate. Roughly 52 to $58 \mathrm{~h}$ postinfection, plates were read by removing $30 \mu \mathrm{l}$ of medium per well, adding $9 \mu \mathrm{l}$ of BrightGlo per well, and measuring RLU on a LUMIstar Omega plate reader after 2 min.

Data availability. The Nextflow pipeline, used to align epitope-mapping sample reads to the reference library, is available at https://github.com/matsengrp/phip-flow. The custom RStudio code generated and used in this study to perform statistical analyses and visualize data is available upon request. Any additional information required to reanalyze the data reported in this paper is also available upon request.

\section{SUPPLEMENTAL MATERIAL}

Supplemental material is available online only.

SUPPLEMENTAL FILE 1, PDF file, $1 \mathrm{MB}$.

\section{ACKNOWLEDGMENTS}

J.O. conceived the project, and H.L.I. and J.O. designed the methodology of the study. H.Y.C. led the HAARVI research study with the involvement of J.K.L., N.F., C.R.W., and D.J.M. for participant scheduling and sample collection. H.Y.C. proposed the inclusion of neutralization in this study. H.L.I., H.W., and C.S.F. performed experiments. H.L.I. and J.G. conducted the data analysis, with the supervision of J.O. and F.A.M. H.L.I. generated data visualizations. J.O. and H.L.I. wrote the paper with input from all authors.

We thank the dedicated HAARVI staff and all participants who contributed samples. We also thank members of the Overbaugh, Matsen, and Chu labs for helpful discussion and feedback.

This work was supported by the following NIH grants: R01 Al138709 awarded to J.O., T32 GM007270 awarded to H.L.I., BMGF Acceleration of COVID-19 Research to H.Y.C., and R01 Al146028 awarded to F.A.M. J.O. also received support as the Endowed Chair for Graduate Education (Fred Hutch). The research of F.A.M. was supported in part by a Faculty Scholar grant from the Howard Hughes Medical Institute and the Simons Foundation. Scientific Computing Infrastructure at Fred Hutch was funded by ORIP grant S100D028685.

H.Y.C. reported consulting with Ellume, Pfizer, The Bill and Melinda Gates Foundation, Glaxo Smith Kline, and Merck. H.Y.C. has also received research funding from Gates Ventures and Sanofi Pasteur, as well as support and reagents from Ellume and Cepheid outside the submitted work. The other authors declare no competing interests.

\section{REFERENCES}

1. Zhang Z, Bi Q, Fang S, Wei L, Wang X, He J, Wu Y, Liu X, Gao W, Zhang R, Gong W, Su Q, Azman AS, Lessler J, Zou X. 2021. Insight into the practical performance of RT-PCR testing for SARS-CoV-2 using serological data: a cohort study. Lancet Microbe 2:e79-e87. https://doi.org/10.1016/S2666 $-5247(20) 30200-7$

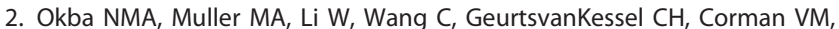
Lamers MM, Sikkema RS, de Bruin E, Chandler FD, Yazdanpanah Y, Le Hingrat Q, Descamps D, Houhou-Fidouh N, Reusken C, Bosch BJ, Drosten C, Koopmans MPG, Haagmans BL. 2020. Severe acute respiratory syndrome coronavirus 2-specific antibody responses in coronavirus disease patients. Emerg Infect Dis 26:1478-1488. https://doi.org/10.3201/eid2607 .200841.

3. Seow J, Graham C, Merrick B, Acors S, Pickering S, Steel KJA, Hemmings O, O'Byrne A, Kouphou N, Galao RP, Betancor G, Wilson HD, Signell AW, Winstone $\mathrm{H}$, Kerridge $\mathrm{C}$, Huettner I, Jimenez-Guardeno JM, Lista MJ, Temperton N, Snell LB, Bisnauthsing K, Moore A, Green A, Martinez L, Stokes B, Honey J, Izquierdo-Barras A, Arbane G, Patel A, Tan MKI, O'Connell L, O'Hara G, MacMahon E, Douthwaite S, Nebbia G, Batra R, Martinez-Nunez R, Shankar-Hari M, Edgeworth JD, Neil SJD, Malim MH, Doores KJ. 2020. Longitudinal observation and decline of neutralizing antibody responses in the three months following SARS-CoV-2 infection in humans. Nat Microbiol 5:1598-1607. https://doi.org/10.1038/s41564 $-020-00813-8$

4. Lumley SF, O'Donnell D, Stoesser NE, Matthews PC, Howarth A, Hatch SB, Marsden BD, Cox S, James T, Warren F, Peck LJ, Ritter TG, de Toledo Z, Warren L, Axten D, Cornall RJ, Jones EY, Stuart DI, Screaton G, Ebner D, Hoosdally S, Chand M, Crook DW, O'Donnell AM, Conlon CP, Pouwels KB, Walker AS, Peto TEA, Hopkins S, Walker TM, Jeffery K, Eyre DW, Oxford
University Hospitals Staff Testing Group. 2021. Antibody status and incidence of SARS-CoV-2 infection in health care workers. N Engl J Med 384: 533-540. https://doi.org/10.1056/NEJMoa2034545.

5. Ebinger JE, Fert-Bober J, Printsev I, Wu M, Sun N, Prostko JC, Frias EC, Stewart JL, Van Eyk JE, Braun JG, Cheng S, Sobhani K. 2021. Antibody responses to the BNT162b2 mRNA vaccine in individuals previously infected with SARS-CoV-2. Nat Med 27:981-984. https://doi.org/10.1038/ s41591-021-01325-6.

6. Krammer F, Srivastava K, Alshammary H, Amoako AA, Awawda MH, Beach KF, Bermudez-Gonzalez MC, Bielak DA, Carreno JM, Chernet RL, Eaker LQ, Ferreri ED, Floda DL, Gleason CR, Hamburger JZ, Jiang K, Kleiner G, Jurczyszak D, Matthews JC, Mendez WA, Nabeel I, Mulder LCF, Raskin AJ, Russo KT, Salimbangon AT, Saksena M, Shin AS, Singh G, Sominsky LA, Stadlbauer D, Wajnberg A, Simon V. 2021. Antibody responses in seropositive persons after a single dose of SARS-CoV-2 mRNA vaccine. N Engl J Med 384:1372-1374. https://doi.org/10.1056/NEJMc2101667.

7. Widge AT, Rouphael NG, Jackson LA, Anderson EJ, Roberts PC, Makhene M, Chappell JD, Denison MR, Stevens LJ, Pruijssers AJ, McDermott AB, Flach B, Lin BC, Doria-Rose NA, O'Dell S, Schmidt SD, Neuzil KM, Bennett H, Leav B, Makowski M, Albert J, Cross K, Edara VV, Floyd K, Suthar MS, Buchanan W, Luke CJ, Ledgerwood JE, Mascola JR, Graham BS, Beigel JH, mRNA-1273 Study Group. 2021. Durability of responses after SARS-CoV-2 mRNA-1273 vaccination. N Engl J Med 384:80-82. https://doi.org/10 .1056/NEJMc2032195.

8. Baden LR, El Sahly HM, Essink B, Kotloff K, Frey S, Novak R, Diemert D, Spector SA, Rouphael N, Creech CB, McGettigan J, Khetan S, Segall N, Solis J, Brosz A, Fierro C, Schwartz H, Neuzil K, Corey L, Gilbert P, Janes H, Follmann D, Marovich M, Mascola J, Polakowski L, Ledgerwood J, Graham 
BS, Bennett H, Pajon R, Knightly C, Leav B, Deng W, Zhou H, Han S, Ivarsson M, Miller J, Zaks T, COVE Study Group. 2021. Efficacy and safety of the mRNA-1273 SARS-CoV-2 vaccine. N Engl J Med 384:403-416. https://doi.org/10.1056/NEJMoa2035389.

9. Polack FP, Thomas SJ, Kitchin N, Absalon J, Gurtman A, Lockhart S, Perez $J$, Pérez Marc G, Moreira ED, Zerbini C, Bailey R, Swanson KA, Roychoudhury S, Koury K, Li P, Kalina WV, Cooper D, Frenck RW, Hammitt LL, Türeci Ö, Nell H, Schaefer A, Ünal S, Tresnan DB, Mather S, Dormitzer PR, Şahin U, Jansen KU, Gruber WC, C4591001 Clinical Trial Group. 2020. Safety and efficacy of the BNT162b2 mRNA Covid-19 vaccine. N Engl J Med 383:2603-2615. https://doi.org/10.1056/NEJMoa2034577.

10. Sadoff J, Gray G, Vandebosch A, Cardenas V, Shukarev G, Grinsztejn B, Goepfert PA, Truyers C, Fennema H, Spiessens B, Offergeld K, Scheper G, Taylor KL, Robb ML, Treanor J, Barouch DH, Stoddard J, Ryser MF, Marovich MA, Neuzil KM, Corey L, Cauwenberghs N, Tanner T, Hardt K, Ruiz-Guinazu J, Le Gars M, Schuitemaker H, Van Hoof J, Struyf F, Douoguih M, ENSEMBLE Study Group. 2021. Safety and efficacy of singledose Ad26.COV2.S vaccine against Covid-19. N Engl J Med 384: 2187-2201. https://doi.org/10.1056/NEJMoa2101544.

11. Voysey M, Clemens SAC, Madhi SA, Weckx LY, Folegatti PM, Aley PK, Angus $B$, Baillie VL, Barnabas SL, Bhorat QE, Bibi S, Briner C, Cicconi $P$, Collins AM, Colin-Jones R, Cutland CL, Darton TC, Dheda K, Duncan CJA, Emary KRW, Ewer KJ, Fairlie L, Faust SN, Feng S, Ferreira DM, Finn A, Goodman AL, Green CM, Green CA, Heath PT, Hill C, Hill H, Hirsch I, Hodgson SHC, Izu A, Jackson S, Jenkin D, Joe CCD, Kerridge $S$, Koen A, Kwatra G, Lazarus R, Lawrie AM, Lelliott A, Libri V, Lillie PJ, Mallory R, Mendes AVA, Milan EP, Minassian AM, Oxford COVID Vaccine Trial Group, et al. 2021. Safety and efficacy of the ChAdOx1 nCoV-19 vaccine (AZD1222) against SARS-CoV-2: an interim analysis of four randomised controlled trials in Brazil, South Africa, and the UK. Lancet 397:99-111. https://doi.org/10.1016/S0140-6736(20)32661-1.

12. Khoury DS, Cromer D, Reynaldi A, Schlub TE, Wheatley AK, Juno JA, Subbarao K, Kent SJ, Triccas JA, Davenport MP. 2021. Neutralizing antibody levels are highly predictive of immune protection from symptomatic SARS-CoV-2 infection. Nat Med 27:1205-1211. https://doi.org/10.1038/ s41591-021-01377-8.

13. Krammer F. 2021. Correlates of protection from SARS-CoV-2 infection. Lancet 397:1421-1423. https://doi.org/10.1016/S0140-6736(21)00782-0.

14. Krammer F. 2020. SARS-CoV-2 vaccines in development. Nature 586: 516-527. https://doi.org/10.1038/s41586-020-2798-3.

15. Liu X, Shaw R, Stuart ASV, Greenland M, Dinesh T, Provstgaard-Morys S, Clutterbuck E, Ramasamy MN, Aley PK, Farooq Mujadidi Y, Long F, Plested E, Robinson H, Singh N, Walker LL, White R, Andrews N, Cameron JC, Collins AM, Ferreira DM, Hill HC, Green CA, Hallis B, Heath PT, Faust SN, Finn A, Lambe T, Lazarus R, Libri V, Ramsay ME, Read RC, Turner DPJ, Turner PJ, Nguyen-Van-Tam JS, Snape MD, Com-COV Study Group. 2021. Safety and immunogenicity report from the Com-COV Study-a singleblind randomised non-inferiority trial comparing heterologous and homologous prime-boost schedules with an adenoviral vectored and mRNA COVID-19 vaccine. Preprints with the Lancet https://papers.ssrn.com/ sol3/papers.cfm?abstract_id=3874014.

16. Wu K, Choi A, Koch M, Elbashir S, Ma L, Lee D, Woods A, Henry C, Palandjian C, Hill A, Quinones J, Nunna N, O'Connell S, McDermott AB, Falcone S, Narayanan E, Colpitts T, Bennett H, Corbett KS, Seder R, Graham BS, Stewart-Jones GB, Carfi A, Edwards DK. 2021. Variant SARSCoV-2 mRNA vaccines confer broad neutralization as primary or booster series in mice. bioRxiv. https://doi.org/10.1101/2021.04.13.439482.

17. Lim MD. 2018. Dried blood spots for global health diagnostics and surveillance: opportunities and challenges. Am J Trop Med Hyg 99:256-265. https://doi.org/10.4269/ajtmh.17-0889.

18. World Health Organization. 2020. WHO manual for HIV drug resistance testing using dried blood spot specimens, 3rd ed. World Health Organization, Geneva, Switzerland.

19. IATA. 2021. Dangerous goods regulations, 62nd ed. https://www.iata.org/ en/publications/dgr/.

20. Gruner N, Stambouli O, Ross RS. 2015. Dried blood spots-preparing and processing for use in immunoassays and in molecular techniques. J Vis Exp. https://doi.org/10.3791/52619.

21. Guthrie R, Susi A. 1963. A simple phenylalanine method for detecting phenylketonuria in large populations of newborn infants. Pediatrics 32: 338-343.

22. Li W, Lee MS. 2014. Dried blood spots: applications and techniques. John Wiley \& Sons, Hoboken, NJ.
23. Freeman JD, Rosman LM, Ratcliff JD, Strickland PT, Graham DR, Silbergeld EK. 2018. State of the science in dried blood spots. Clin Chem 64:656-679. https://doi.org/10.1373/clinchem.2017.275966.

24. Smit PW, Elliott I, Peeling RW, Mabey D, Newton PN. 2014. An overview of the clinical use of filter paper in the diagnosis of tropical diseases. Am J Trop Med Hyg 90:195-210. https://doi.org/10.4269/ajtmh.13-0463.

25. Snijdewind IJ, van Kampen JJ, Fraaij PL, van der Ende ME, Osterhaus AD, Gruters RA. 2012. Current and future applications of dried blood spots in viral disease management. Antiviral Res 93:309-321. https://doi.org/10 .1016/j.antiviral.2011.12.011.

26. Bertagnolio S, Parkin NT, Jordan M, Brooks J, Garcia-Lerma JG. 2010. Dried blood spots for HIV-1 drug resistance and viral load testing: a review of current knowledge and WHO efforts for global HIV drug resistance surveillance. AIDS Rev 12:195-208.

27. Moat SJ, Zelek WM, Carne E, Ponsford MJ, Bramhall K, Jones S, ElShanawany T, Wise MP, Thomas A, George C, Fegan C, Steven R, Webb R, Weeks I, Morgan BP, Jolles S. 2021. Development of a high-throughput SARS-CoV-2 antibody testing pathway using dried blood spot specimens. Ann Clin Biochem 58:123-131. https://doi.org/10.1177/0004563220981106.

28. Karp DG, Danh K, Espinoza NF, Seftel D, Robinson PV, Tsai CT. 2020. A serological assay to detect SARS-CoV-2 antibodies in at-home collected finger-prick dried blood spots. Sci Rep 10:20188. https://doi.org/10.1038/ s41598-020-76913-6.

29. Weisser H, Steinhagen K, Hocker R, Borchardt-Loholter V, Anvari O, Kern PM. 2021. Evaluation of dried blood spots as alternative sampling material for serological detection of anti-SARS-CoV-2 antibodies using established ELISAs. Clin Chem Lab Med 59:979-985. https://doi.org/10.1515/ cclm-2020-1436.

30. Toh ZQ, Higgins RA, Anderson J, Mazarakis N, Do LAH, Rautenbacher K, Ramos P, Dohle K, Tosif S, Crawford N, Mulholland K, Licciardi PV. 2021. The use of dried blood spots for the serological evaluation of SARS-CoV-2 antibodies. J Public Health (Oxf). https://doi.org/10.1093/pubmed/fdab011.

31. Mulchandani R, Brown B, Brooks T, Semper A, Machin N, Linley E, Borrow R, Wyllie D, EDSAB-HOME Study Investigators. 2021. Use of dried blood spot samples for SARS-CoV-2 antibody detection using the Roche Elecsys high throughput immunoassay. J Clin Virol 136:104739. https://doi.org/ 10.1016/j.jcv.2021.104739.

32. Zava TT, Zava DT. 2021. Validation of dried blood spot sample modifications to two commercially available COVID-19 lgG antibody immunoassays. Bioanalysis 13:13-28. https://doi.org/10.4155/bio-2020-0289.

33. Morley GL, Taylor S, Jossi S, Perez-Toledo M, Faustini SE, Marcial-Juarez E, Shields AM, Goodall M, Allen JD, Watanabe $Y$, Newby ML, Crispin M, Drayson MT, Cunningham AF, Richter AG, O'Shea MK. 2020. Sensitive detection of SARS-CoV-2-specific antibodies in dried blood spot samples. Emerg Infect Dis 26:2970-2973. https://doi.org/10.3201/eid2612.203309.

34. McDade TW, McNally EM, Zelikovich AS, D'Aquila R, Mustanski B, Miller A, Vaught LA, Reiser NL, Bogdanovic E, Fallon KS, Demonbreun AR. 2020. High seroprevalence for SARS-CoV-2 among household members of essential workers detected using a dried blood spot assay. PLoS One 15: e0237833. https://doi.org/10.1371/journal.pone.0237833.

35. Turgeon CT, Sanders KA, Granger D, Nett SL, Hilgart H, Matern D, Theel ES. 2021. Detection of SARS-CoV-2 IgG antibodies in dried blood spots. Diagn Microbiol Infect Dis 101:115425. https://doi.org/10.1016/j.diagmicrobio .2021.115425.

36. Turgeon CT, Sanders KA, Rinaldo P, Granger D, Hilgart $H$, Matern D, Theel ES. 2021. Validation of a multiplex flow immunoassay for detection of lgG antibodies against SARS-CoV-2 in dried blood spots. PLoS One 16: e0252621. https://doi.org/10.1371/journal.pone.0252621.

37. Amanat F, Stadlbauer D, Strohmeier S, Nguyen THO, Chromikova V, McMahon M, Jiang K, Arunkumar GA, Jurczyszak D, Polanco J, BermudezGonzalez M, Kleiner G, Aydillo T, Miorin L, Fierer DS, Lugo LA, Kojic EM, Stoever J, Liu STH, Cunningham-Rundles C, Felgner PL, Moran T, GarciaSastre A, Caplivski D, Cheng AC, Kedzierska K, Vapalahti O, Hepojoki JM, Simon V, Krammer F. 2020. A serological assay to detect SARS-CoV-2 seroconversion in humans. Nat Med 26:1033-1036. https://doi.org/10.1038/ s41591-020-0913-5.

38. Stadlbauer D, Amanat F, Chromikova V, Jiang K, Strohmeier S, Arunkumar GA, Tan J, Bhavsar D, Capuano C, Kirkpatrick E, Meade P, Brito RN, Teo C, McMahon M, Simon V, Krammer F. 2020. SARS-CoV-2 seroconversion in humans: a detailed protocol for a serological assay, antigen production, and test setup. Curr Protoc Microbiol 57:e100. https://doi.org/10.1002/ cpmc. 100.

39. Stoddard Cl, Galloway J, Chu HY, Shipley MM, Sung K, Itell HL, Wolf CR, Logue JK, Magedson A, Garrett ME, Crawford KHD, Laserson U, Matsen 
FA, IV, Overbaugh J. 2021. Epitope profiling reveals binding signatures of SARS-CoV-2 immune response in natural infection and cross-reactivity with endemic human CoVs. Cell Rep 35:109164. https://doi.org/10.1016/j .celrep.2021.109164.

40. Crawford KHD, Dingens AS, Eguia R, Wolf CR, Wilcox N, Logue JK, Shuey K, Casto AM, Fiala B, Wrenn S, Pettie D, King NP, Greninger AL, Chu HY, Bloom JD. 2021. Dynamics of neutralizing antibody titers in the months after SARS-CoV-2 infection. J Infect Dis 223:197-205. https://doi.org/10 .1093/infdis/jiaa618.

41. Addetia A, Crawford KHD, Dingens A, Zhu H, Roychoudhury $P$, Huang ML, Jerome KR, Bloom JD, Greninger AL. 2020. Neutralizing antibodies correlate with protection from SARS-CoV-2 in humans during a fishery vessel outbreak with a high attack rate. J Clin Microbiol 58:e02107-20. https:// doi.org/10.1128/JCM.02107-20.

42. Daag JV, Ylade M, Jadi R, Adams C, Cuachin AM, Alpay R, Aportadera ETC, Yoon IK, de Silva AM, Lopez AL, Deen J. 2021. Performance of dried blood spots compared with serum samples for measuring dengue seroprevalence in a cohort of children in Cebu, Philippines. Am J Trop Med Hyg 104:130-135. https://doi.org/10.4269/ajtmh.20-0937.

43. Fachiroh J, Prasetyanti PR, Paramita DK, Prasetyawati AT, Anggrahini DW, Haryana SM, Middeldorp JM. 2008. Dried-blood sampling for Epstein-Barr virus immunoglobulin $\mathrm{G}(\mathrm{lgG})$ and $\lg A$ serology in nasopharyngeal carcinoma screening. J Clin Microbiol 46:1374-1380. https://doi.org/10 .1128/JCM.01368-07.

44. Stefic K, Guinard J, Peytavin G, Saboni L, Sommen C, Sauvage C, Lot F, Laperche S, Velter A, Barin F. 2019. Screening for human immunodeficiency virus infection by use of a fourth-generation antigen/antibody assay and dried blood spots: in-depth analysis of sensitivity and performance assessment in a cross-sectional study. J Clin Microbiol 58:e01645-19. https://doi.org/10.1128/JCM.01645-19.

45. Mohan D, Wansley DL, Sie BM, Noon MS, Baer AN, Laserson U, Larman HB. 2018. PhIP-Seq characterization of serum antibodies using oligonucleotide-encoded peptidomes. Nat Protoc 13:1958-1978. https://doi.org/10 .1038/s41596-018-0025-6.

46. Dingens AS, Crawford KHD, Adler A, Steele SL, Lacombe K, Eguia R, Amanat F, Walls AC, Wolf CR, Murphy M, Pettie D, Carter L, Qin X, King NP, Veesler D, Krammer F, Dickerson JA, Chu HY, Englund JA, Bloom JD. 2020. Serological identification of SARS-CoV-2 infections among children visiting a hospital during the initial Seattle outbreak. Nat Commun 11:4378. https://doi.org/10.1038/s41467-020-18178-1.

47. Williams KL, Stumpf M, Naiman NE, Ding S, Garrett M, Gobillot T, Vezina D, Dusenbury K, Ramadoss NS, Basom R, Kim PS, Finzi A, Overbaugh J. 2019. Identification of HIV gp41-specific antibodies that mediate killing of infected cells. PLoS Pathog 15:e1007572. https://doi.org/10.1371/journal .ppat. 1007572 . 